Journal of Physical Science, Vol. 28(2), 127-141, 2017

\title{
Microstructural, Optical and Ethanol Sensing Characteristics of CBD-synthesised AgO Thin Film: Influence of Bath Temperature
}

\author{
Mahima Ranjan Das and Partha Mitra* \\ Department of Physics, University of Burdwan, Golapbag, Burdwan-713104, India \\ *Corresponding author: mitrapartha1@rediffmail.com
}

Published online: 15 August 2017

To cite this article: Das, M. R. \& Mitra, P. (2017). Microstructural, optical and ethanol sensing characteristics of CBD-synthesised $\mathrm{AgO}$ thin film: Influence of bath temperature. J. Phys. Sci., 28(2), 127-141, https://doi.org/10.21315/jps2017.28.2.9

To link to this article: https://doi.org/10.21315/jps2017.28.2.9

\begin{abstract}
Polycrystalline thin films of silver oxide were synthesised by chemical bath deposition (CBD) technique. The particle size in the deposited films was found to decrease with increasing bath temperature while the porosity was found to increase with increasing temperature of deposition. The band gap in the film was found to increase with decreasing particle size. The sensitivity in the presence of alcohol was found to increase with working temperature before reaching maximum at $250^{\circ} \mathrm{C}$. A maximum sensitivity of $\sim 35 \%$ was observed at $250^{\circ} \mathrm{C}$ in presence of $1000 \mathrm{ppm}$ ethanol for films deposited at highest deposition temperature.
\end{abstract}

Keywords: AgO thin film, $\mathrm{CBD}, \mathrm{XRD}$, band gap, alcohol sensing

\section{INTRODUCTION}

Nano crystalline silver oxide thin films have attracted great attention of several researchers due to its unique physiochemical, electrochemical, electronic and optical properties. Some of the important applications of silver oxide thin films are in the field of flat panel displays, ultra-high density optical data storage devices, plasmon photonic devices, organic light-emitting diodes, sensors for gas detection, anti-bacterial coating, active cathode materials in alkaline batteries, and as photovoltaic material..$^{1-8}$

As silver is a multivalent atom, it forms various phases like $\mathrm{Ag}_{2} \mathrm{O}, \mathrm{AgO}, \mathrm{Ag}_{3} \mathrm{O}_{4}$, $\mathrm{Ag}_{4} \mathrm{O}_{3}$, and $\mathrm{Ag}_{2} \mathrm{O}_{3}$ by interacting with oxygen atom. The formation of a phase 
depends upon reaction condition of the growth mechanism. Among these, most stable phases are $\mathrm{Ag}_{2} \mathrm{O}$ and $\mathrm{AgO}$. Silver oxide has been reported to be a p-type semiconductor with direct band gap ranging from 1.2 to $3.4 \mathrm{eV}$ depending on the deviation in structure, stoichiometry and crystalline phase, which in turn depends on deposition technique employed to synthesise the film. Different deposition techniques employed by researchers include thermal evaporation, pulsed laser deposition, chemical vapor deposition (CVD), RF sputtering, DC sputtering, electron beam evaporation, and chemical bath deposition (CBD). ${ }^{9-16}$ Physical techniques (such as sputtering, evaporation, etc.) require vacuum and high temperatures which limit their practical applications. CBD, a chemical solution process, yields stable, adherent, uniform and hard films with good reproducibility and is suitable for preparing highly efficient thin films in a simple and cost effective way. The growth of thin films by CBD strongly depends on growth conditions, such as duration of deposition, composition and temperature of the bath solution.

In this present work, we have deposited $\mathrm{AgO}$ thin films by $\mathrm{CBD}$ method with varying deposition temperature $\left(60^{\circ} \mathrm{C}-80^{\circ} \mathrm{C}\right)$. The influence of deposition temperature on structural, morphological and optical band gap was reported. Also, alcohol (ethanol) sensing characteristics of the films were studied. Alcohol is an organic solvent which is broadly applied in many industries and research laboratories such as in automotive fuels, developing of coloured materials, dyes and pigments, drugs and medicines, aromas and perfumes, etc. However, it is toxic and long-term exposure to alcohol vapour can result in diseases such as eyesight trouble and nerve diseases. Owing to its large-scale applications, toxicity and clinical applications, the improvement of a simple and reliable ethanol sensor has become essential. To the best of our knowledge, this is the first report for detection of ethanol with silver oxide thin films. Primarily $\mathrm{SnO}_{2}, \mathrm{CuO}, \mathrm{ZnO}$ and $\mathrm{Fe}_{2} \mathrm{O}_{3}$ have been used by researchers for ethanol sensing which generally requires high operating temperatures. Although $\mathrm{ZnO}$ has been reported to show significant ethanol sensitivity at low temperature $\left(120^{\circ} \mathrm{C}-140^{\circ} \mathrm{C}\right), \mathrm{SnO}_{2}$ was reported to show high sensitivity to low concentrations of ethanol in the temperature range $420^{\circ} \mathrm{C}-450^{\circ} \mathrm{C}, \mathrm{Fe}_{2} \mathrm{O}_{3}$ was reported to show high sensitivity at $350^{\circ} \mathrm{C}$ and $\mathrm{CuO}$ was reported to show maximum sensitivity at $400^{\circ} \mathrm{C}(15.4 \%) .{ }^{17-20} \mathrm{ZnO}$ was synthesised by Pulsed LASER deposition and spray pyrolysis in those works. ${ }^{17,18}$ The primary objective of the present work was to synthesise AgO thin films by cost effective CBD method and to check their potentiality as ethanol sensor. 


\section{EXPERIMENTAL}

Silver peroxide $(\mathrm{AgO})$ thin films were synthesised on pre-cleaned biological glass slide substrates by CBD method. Before deposition glass substrates were degreased in nitric acid for $24 \mathrm{~h}$, washed with detergent, and ultra-sonically cleaned using alcohol and dried in air. Two gram of silver nitrate $\mathrm{A}_{\mathrm{g}} \mathrm{NQ}_{3}$ was dissolved in $10 \mathrm{ml}$ of distilled water in a beaker. Then, $5 \mathrm{ml}$ of triethanolamine $\left(\mathrm{C}_{6} \mathrm{H}_{15} \mathrm{NO}_{3}\right)$ (commonly known as TEA) was added drop wise in the solution under continuous stirring in a magnetic stirrer. TEA was used as a complexing agent which turned the brownish solution colourless. ${ }^{22}$ Final solution volume was made $100 \mathrm{ml}$ by addition of distilled water. The bath solution was kept on a hot plate and the glass slide was placed vertically into the beaker. After suitable deposition time (90 min), the slides were removed from the bath, rinsed with distilled water, and dried in air. Three thin films of silver peroxide were synthesised by variation of bath solution temperature from $60^{\circ} \mathrm{C}$ to $80^{\circ} \mathrm{C}$ in steps of $10^{\circ} \mathrm{C}$. Silver nitrate forms a complex in presence of the complexing agent in the solution which serves as source of $\mathrm{Ag}^{2+}$ ion. The silver ion reacts with hydroxyl ion $\left(\mathrm{OH}^{-}\right)$present in the solution to give silver hydroxide (oxyhydroxide intermediate). The synthesised films were finally heat treated in air at $250^{\circ} \mathrm{C}$ for conversion to silver oxide. Heat treatment also leads to better adhesion.

The thickness of $\mathrm{AgO}$ films was measured by commonly used weight difference method using a sensitive microbalance as reported by Mitra and Khan. ${ }^{23}$ The method involves measuring the weight of the substrate before and after film deposition. Thus if $W_{1}$ and $W_{2}$ be the weights of the substrate before and after film deposition in gm, $A$ is the area of film deposition in $\mathrm{cm}^{2}$ and $\rho$ be the theoretical density, then the film thickness can be evaluated from the equation:

$$
d=\frac{\left(W_{2}-W_{1}\right)}{A \rho} \times 10^{-4} \mu \mathrm{m}
$$

Film thickness was calculated using the theoretical density of $7.3 \mathrm{gm} / \mathrm{cm}^{3}$ for AgO. ${ }^{24}$ The thickness of the film was found to increase with deposition temperature. The estimated thicknesses were $\sim 210 \mathrm{~nm}, \sim 340 \mathrm{~nm}$ and $\sim 430 \mathrm{~nm}$ for films deposited at $60^{\circ} \mathrm{C}, 70^{\circ} \mathrm{C}$ and $80^{\circ} \mathrm{C}$ bath temperature respectively. The gravimetry method of film thickness determination has some limitations because of non-uniformity, porosity and edge tapering effects in chemically deposited films with porous microstructure. The actual density of the film is always lower than the theoretical density used in gravimetry technique which does not takes account of porosity. Thus the actual thickness is always greater than the measured one using theoretical 
density. However, this error does not affect the comparative data of measured film thickness.

The phase identification and crystalline properties of the samples were studied by X-ray diffraction (XRD) method with the help of a Bruker (D8 advance) X-ray diffract meter using Ni-filtered $\mathrm{CuK}_{a}$ radiation $(\lambda=1.5418 \AA)$. The diffraction data were recorded in the range $20^{\circ}-80^{\circ}$ scattering angle and the experimental peak positions were compared with standard Joint Committee of Powder Diffraction System (JCPDS) files. UV-VIS photometric measurements were taken using a double-beam spectrophotometer (Shimadzu, UV-1800) at room temperature. The spectra were recorded by using a similar glass as a reference and hence, the absorption only due to the film was obtained. The band gap of the films was calculated from the absorption edge of the spectrum.

Gas sensing property was carried out using static gas sensing arrangement in a home-made two-probe assembly housed inside glass. Sensors were tested in a chamber that allowed temperature control and gas flow. Ethanol was injected by a micro syringe into the test chamber and the sensing characteristics of the sensor were then observed by measuring the electrical resistance change of sensor when the latter was exposed to ethanol. The target gas concentration was varied in the range 200-1200 ppm by varying the injection level. Upon the exposure to ethanol the resistance of the material decreases. The sensitivity is defined as: ${ }^{25}$

$$
S \%=\frac{\left|R_{a i r}-R_{g a s}\right|}{R_{a i r}} \times 100
$$

where $R_{a i r}$ and $R_{\text {gas }}$ represent the equilibrium sample resistance in ambient air and under test gas respectively. The sensor resistance was allowed to equilibrate in air for a reasonable time ( $\sim 30 \mathrm{~min})$ to get a stable value of $R_{\text {air }}$. Target gas was injected after a stable value of $R_{\text {air }}$ was reached.

\section{RESULTS AND DISCUSSION}

Figure 1 shows the XRD pattern of AgO thin films deposited at different deposition temperatures. The observed diffraction peaks were compared with standard JCPDS-ICPD diffraction patterns from PDF-2 sets 1-43 database as reported by Ifeanyichukwu..$^{26}$ The major diffraction peak at $\sim 38.52^{\circ}$ corresponds to reflection from (111) diffraction plane. The four minor peaks at $\sim 32.72^{\circ}, \sim 44.84^{\circ}, \sim 64.84^{\circ}$ and $\sim 77.83^{\circ}$ correspond to the reflection from (002), (200), (220) and (311) diffraction plane respectively. The XRD data confirmed polycrystalline cubic 
phase of silver oxide. The crystallite size (D) was calculated using well known Scherrer's formula: ${ }^{27,28}$

$$
D=\frac{k \lambda}{\beta \cos \theta}
$$

where $\lambda$ is the wavelength of radiation used, $k$ is the Scherrer's constant, $\beta$ is the full width at half maximum (FWHM) intensity of the diffraction peak for which the particle size is to be calculated, and $\theta$ is the diffraction angle of the concerned diffraction peak. The estimated particle size for highest intense peak is $\sim 10 \mathrm{~nm}$, $\sim 8 \mathrm{~nm}$ and $\sim 5.5 \mathrm{~nm}$ for films deposited at $60^{\circ} \mathrm{C}, 70^{\circ} \mathrm{C}$ and $80^{\circ} \mathrm{C}$ bath temperature respectively. In this connection it must be mentioned that instrumental and strain broadening was not taken into account while finding the particle size. Thus the measured particle size is always on the lower side (at most 20\%) of the actual particle size. Decrease in grain size with increasing bath temperature indicated more polycrystallinity of the films at higher deposition temperature.

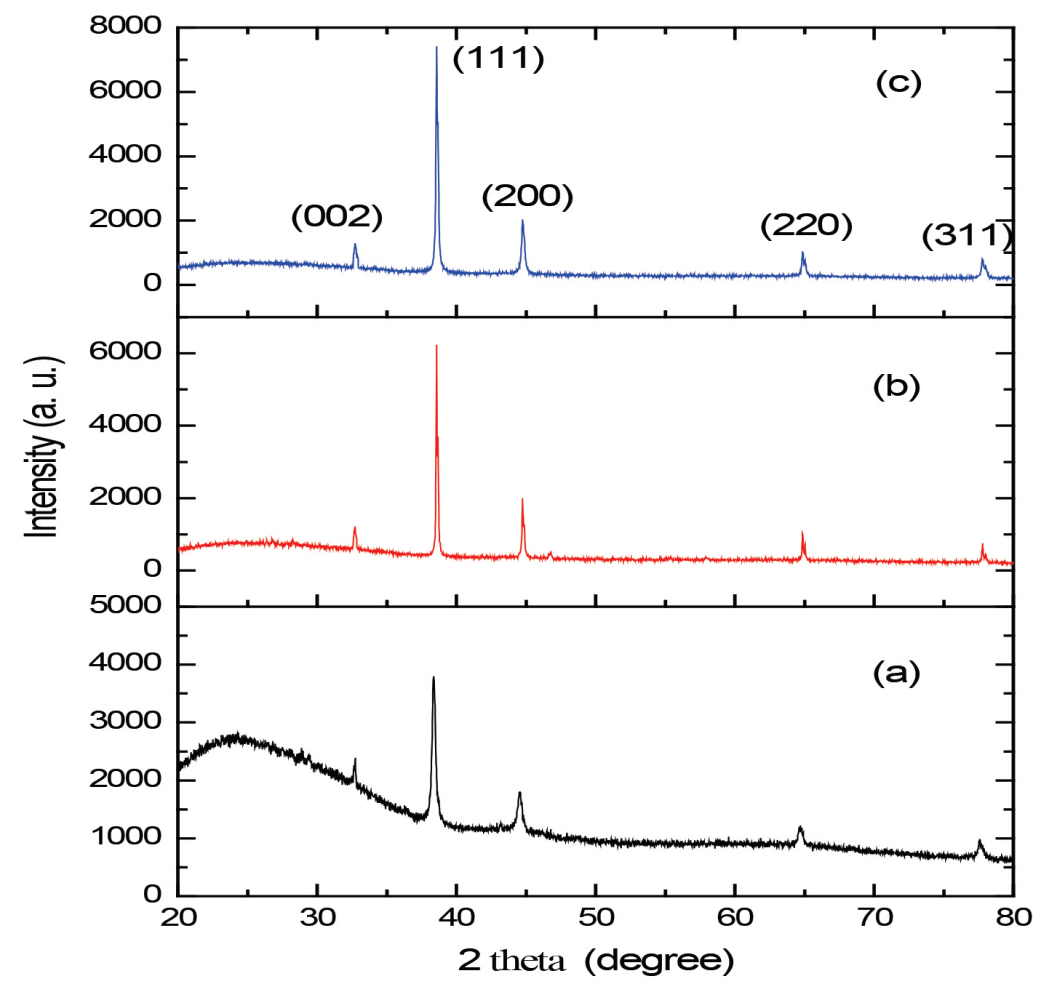

Figure 1: XRD pattern for films deposited at $60^{\circ} \mathrm{C}$ (a), $70^{\circ} \mathrm{C}$ (b) and $80^{\circ} \mathrm{C}$ (c) bath temperature respectively. 
The strain $(\varepsilon)$ in the films were determined using the following formula: ${ }^{29}$

$$
\varepsilon=\frac{\beta \cos \theta}{4}
$$

The estimated values of strain were $\sim 2.13 \times 10^{-3}, \sim 2.75 \times 10^{-3}$ and $\sim 3.23 \times 10^{-3}$ for films deposited at $60^{\circ} \mathrm{C}, 70^{\circ} \mathrm{C}$ and $80^{\circ} \mathrm{C}$ bath temperature respectively. The increase in strain might be the reason for lowering of particle size for films deposited at enhanced bath temperatures. Thus, strain enhancement in turn has beneficial effect on surface related properties (such as sensing) since lowering of particle size is equivalent to an exaggerated surface effect.

The optical absorption spectrum (absorbance as a function of wavelength) was recorded using UV-VIS spectrophotometer measurements. The optical band gap $\left(E_{g}\right)$ was estimated from the plots of $(\alpha h v)^{2}$ versus photon energy $(h v)$ using Tauc's relation: ${ }^{30}$

$$
(\alpha h v)=A\left(h v-E_{g}\right)^{n}
$$

where $A$ is a constant, $\alpha$ is the absorption coefficient and $n$ depends on the nature of transition. For direct transitions $n=1 / 2$ or $2 / 3$, while for indirect ones $n=2$ or 3 , depending on whether they are allowed or forbidden. The best fit of experimental data was obtained for $n=1 / 2$ corresponding to direct band gap energy. The optical band gap energy was obtained by extrapolating the linear regions of the plot on the photon energy axis (Figure 2). The estimated values of band gaps were $\sim 1.46 \mathrm{eV}, \sim 1.55 \mathrm{eV}$ and $\sim 1.64 \mathrm{eV}$ for films deposited at $60^{\circ} \mathrm{C}, 70^{\circ} \mathrm{C}$ and $80^{\circ} \mathrm{C}$ bath temperatures respectively. Enhancement of band gap might be due to decrease in particle size for enhanced bath temperature deposited films showing signature of quantum confinement effect. The optical band gap has been reported to depend on stoichiometry and density of states (DOS) of valance band and conduction band. ${ }^{31}$ No attempt to find stoichiometry (by EDX) or theoretical modelling to find DOS has been made in the present work. Enhancement of absorbance with deposition temperature is due to enhanced thickness. Conversely, increase of thickness lowers transmittance in the films. The obtained value of band gap compares well with reported ones for $\mathrm{AgO}$ film as reported by Nwanya et al. ${ }^{22}$ 


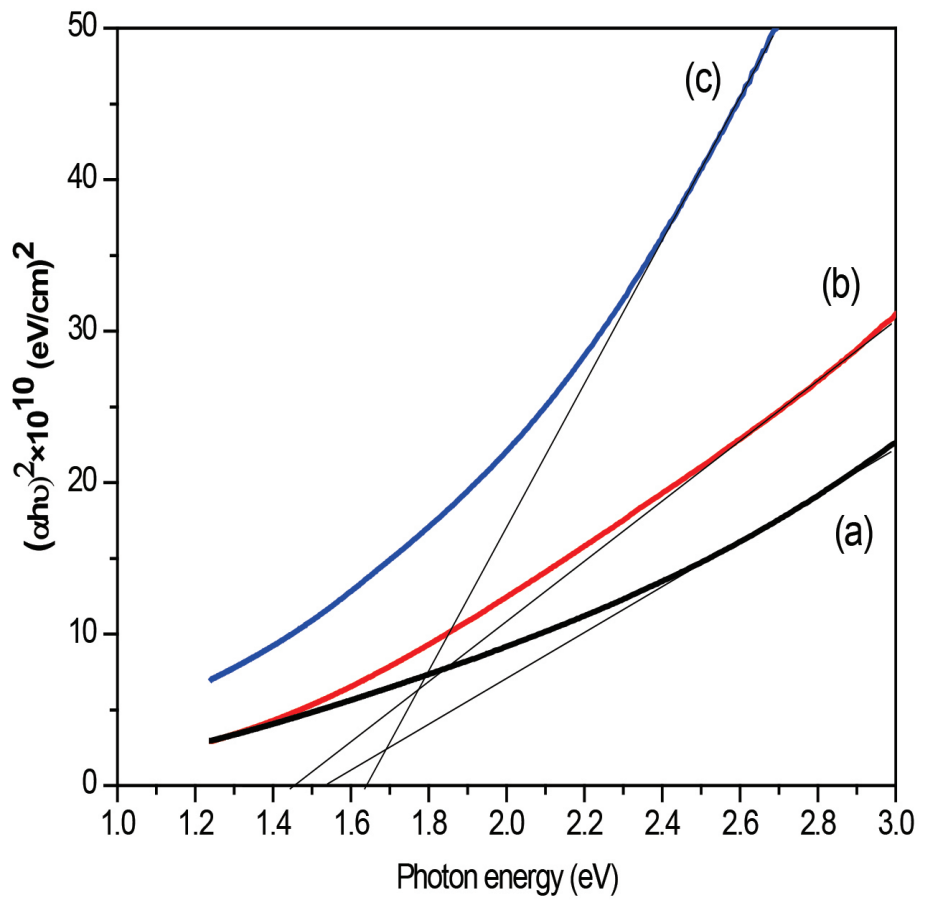

Figure 2: Tauc's plot for films deposited at $60^{\circ} \mathrm{C}$ (a), $70^{\circ} \mathrm{C}$ (b) and $80^{\circ} \mathrm{C}$ (c) bath temperature respectively.

Figure 3 shows the FESEM images of AgO thin films deposited at different bath temperatures. The figure shows a general view of the morphology of the films. The microstructure consisting of off spherical grains and agglomeration of small crystallites in all the samples is evident from the figure. It is difficult to have any idea about the particle size from FESEM images since the particles (small crystallites) agglomerates to create coarse grains in the pictures. Films deposited at $60^{\circ} \mathrm{C}$ shows compact interconnected grains with low porosity. However, with enhanced temperature of deposition, such compactness is lost leading to enhanced porosity. Thus, bath temperature significantly influences the morphology of the films by reducing interconnectivity and compactness of the grains and thereby increasing porosity. Such porous films with small particle size is particularly suitable for gas sensing applications. 

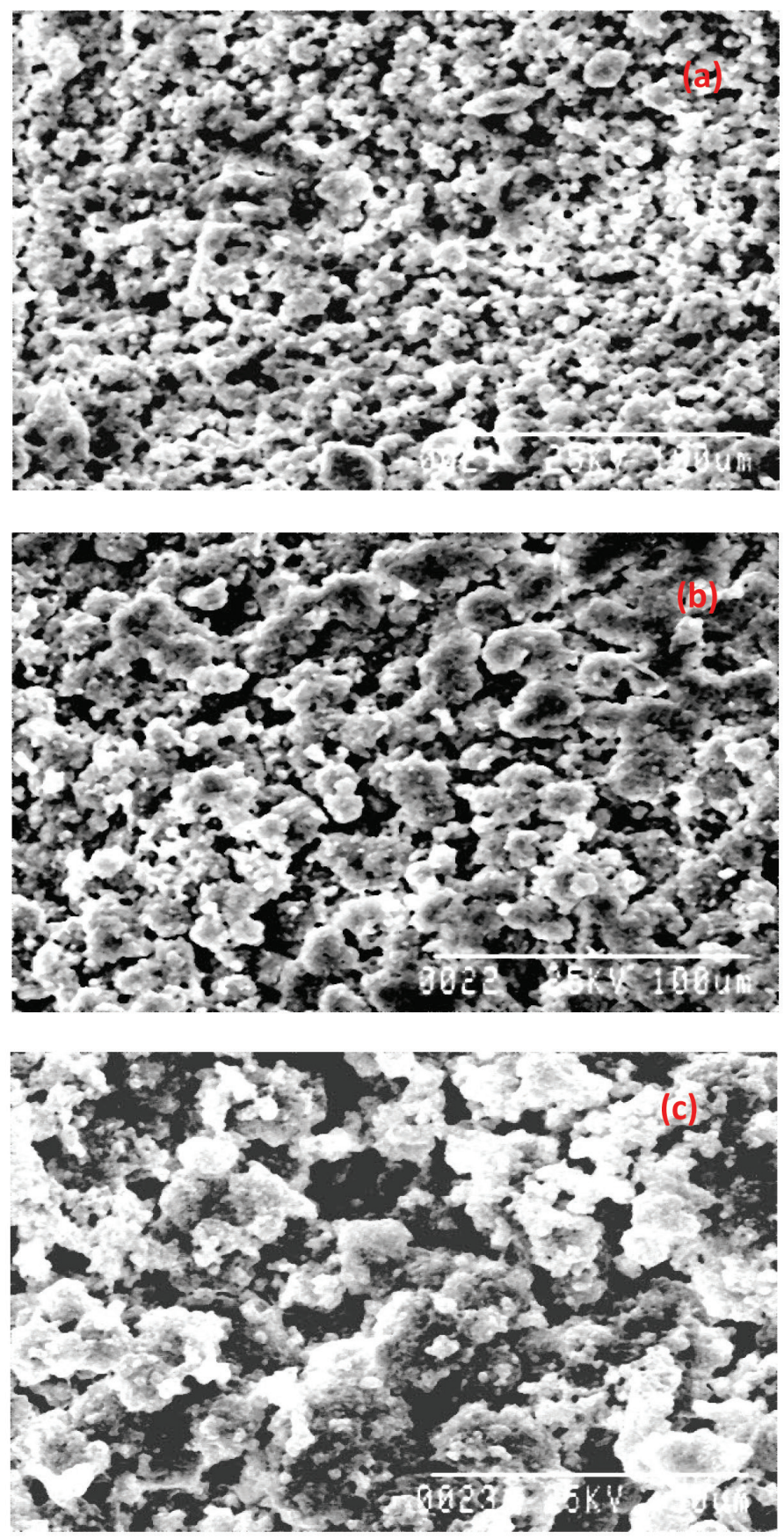

Figure 3: SEM image for films deposited at $60^{\circ} \mathrm{C}$ (a), $70^{\circ} \mathrm{C}$ (b) and $80^{\circ} \mathrm{C}$ (c) bath temperature respectively. 
Figure 4 shows the dependence of ethanol gas sensitivity of $\mathrm{AgO}$ thin film at different temperature. The target gas concentration was $200 \mathrm{ppm}$ (parts per million) in air. Highest sensitivity was obtained at $250^{\circ} \mathrm{C}$ for all the films. The sensitivity increased with increase of bath temperature which is due the increase of porosity and decrease of particle size of the film deposited with bath higher temperature. Lowering of particle size results in larger specific surface area. The specific surface area $(\mathrm{A})$ is related to particle size according to the equation: $:^{32}$

$$
A=\frac{6}{d D}
$$

where $d$ is the bulk density of the material and $D$ is the average particle size. The number 6 is the shape factor. The reduction of particle size from $\sim 10 \mathrm{~nm}$ for $60^{\circ} \mathrm{C}$ bath temperature deposited film to $\sim 5.5 \mathrm{~nm}$ for $80^{\circ} \mathrm{C}$ bath temperature deposited film clearly shows a large enhancement in specific surface area for the latter case. Also, the bulk density in the sample depends on porosity. Enhancement in porosity for higher bath temperature deposited film indicates reduction of density in the sample which in turn increases the specific surface area. No attempt was made to find the porosity (and hence bulk density) in the present work. Only qualitatively we can conclude that decrease in particle size and decrease in bulk density observed in our present experiment clearly indicate enhancement of specific surface area. Enhancement in specific surface area implies higher surface-tovolume ratio and an exaggerated surface effect. As sensing is essentially a surface phenomenon involving reaction between target gas molecule and chemisorbed oxygen species at the surface, exaggerated surface effect leads to enhanced number of chemisorbed species and thereby increasing the sensitivity. The gas sensing mechanism normally accepted for semiconducting oxides assumes that the oxygen adsorbed on the surface of the material traps conduction electrons and thus increases the material's resistivity. ${ }^{33}$ The surface adsorbed oxygen species thus becomes negatively charged chemisorbed speciesor $\left(\mathrm{O}_{2}^{-}\right.$or $\left.\mathrm{O}^{-}\right)$and acts as reaction centres for gas molecules. When reduction gas molecules come in contact with this surface, they interact with this chemisorbed oxygen species, leading to an inverse charge transference and enhanced conductivity. ${ }^{34}$ The reaction mechanism for ethanol with surface adsorbed species leading to the final products $\mathrm{CO}_{2}$ and $\mathrm{H}_{2} \mathrm{O}$ can be represented as follows:

$$
\begin{aligned}
& \mathrm{C}_{2} \mathrm{H}_{5} \mathrm{OH}+2 \mathrm{O}_{2}^{-}=2 \mathrm{CO}_{2}+3 \mathrm{H}_{2} \mathrm{O}+e \\
& \mathrm{C}_{2} \mathrm{H}_{5} \mathrm{OH}+4 \mathrm{O}^{-}=2 \mathrm{CO}_{2}+3 \mathrm{H}_{2} \mathrm{O}+e
\end{aligned}
$$


The electron released in the process goes to conduction band and decreases the resistance of the material. Withdrawal of the target gas results in increase of resistance (re-adsorption of oxygen and re-trapping of electrons) and the material finally comes back to original resistance in air.

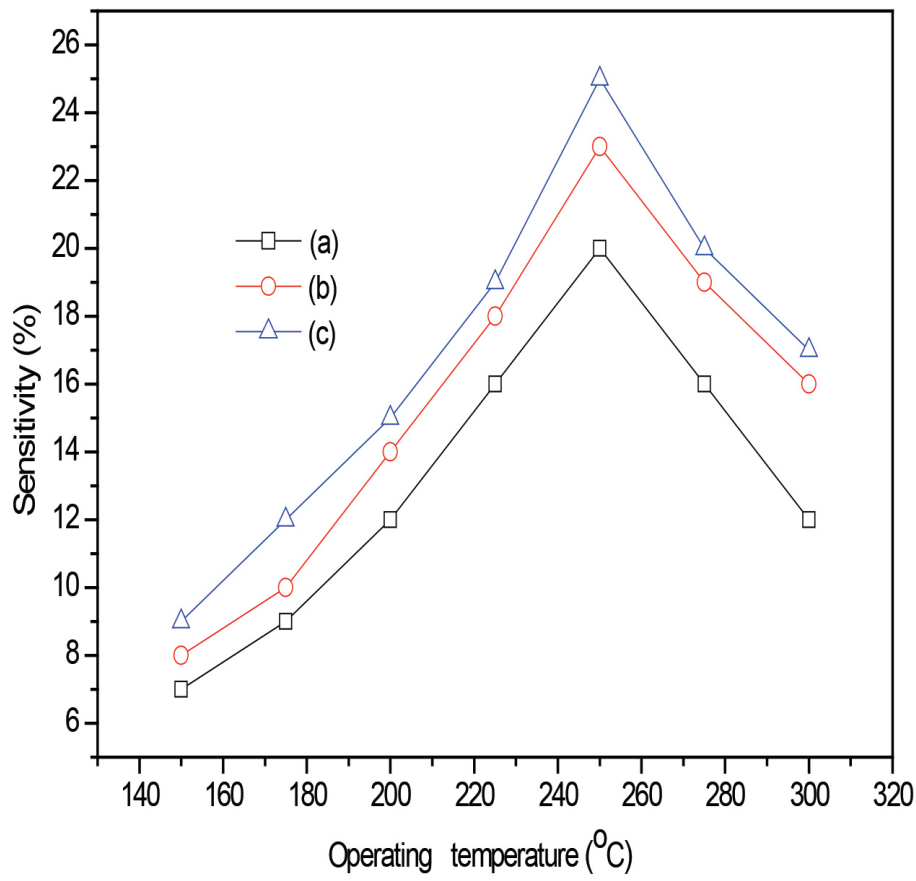

Figure 4: Plot of sensitivity with operating temperature with $200 \mathrm{ppm}$ alcohol concentration for films deposited at (a) $60^{\circ} \mathrm{C}$, (b) $70^{\circ} \mathrm{C}$ and (c) $80^{\circ} \mathrm{C}$ bath temperature respectively.

Thus, the increase of sensitivity with temperature up to a particular temperature may be attributed to the increase of oxygen species concentration on the surface and sufficient conversion of absorbed oxygen into negatively charged chemisorbed species $\left(\mathrm{O}_{2}^{-}\right.$or $\left.\mathrm{O}^{-}\right){ }^{35}$ The decrease in response after attaining a maximum is attributed to reduction of gas adsorption ability beyond a certain temperature. ${ }^{36}$

Figure 5 shows the variation of sensitivity with operating temperature at different ethanol concentration for film deposited at $80^{\circ} \mathrm{C}$ bath temperature. Inset shows the variation of maximum sensitivity (obtained by $250^{\circ} \mathrm{C}$ ) against ethanol concentration in the range 200-1220 ppm. For small concentration of alcohol, the surface reaction rate is low due to the lower coverage of gas molecules on the film surface. An increase in gas concentration enhances the surface reaction 
rate and thus sensitivity increases. At higher concentrations, saturation is reached due to full surface coverage with test gas molecules. The maximum sensitivity observed was $\sim 35 \%$ for 1000 ppm concentration of target gas (see inset) beyond which saturation effect appears. Although no systematic study was carried out on selectivity, the material was found to show little sensitivity to $1000 \mathrm{ppm}$ concentration of acetone $\left(\sim 10 \%\right.$ at $\left.250^{\circ} \mathrm{C}\right)$ and was almost insensitive to ammonia.

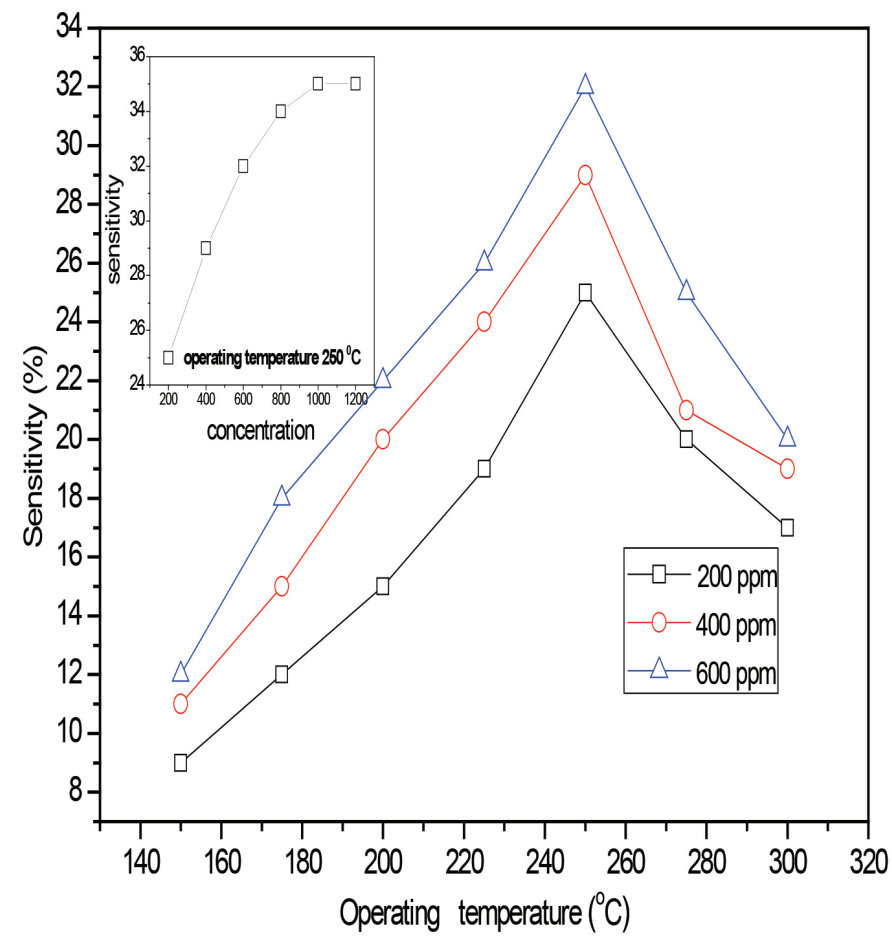

Figure 5: The variation of sensitivity with operating temperature at different alcohol concentration and inset of the figure shows the variation of sensitivity with alcohol concentration for film deposited at $80^{\circ} \mathrm{C}$ bath temperature.

Figure 6 shows the response and recovery characteristics of $80^{\circ} \mathrm{C}$ bath temperature deposited $\mathrm{AgO}$ thin film at $250^{\circ} \mathrm{C}$ in presence of $400 \mathrm{ppm}$ alcohol. The resistance decreases on exposure to target gas and finally saturates with time i.e., reaches $R_{\text {gas }}$ value in presence of target gas. The $R_{\text {gas }}$ value was $\sim 4.4 \mathrm{M} \Omega$ and the $R_{\text {air }}$ value was $6.2 \mathrm{M} \Omega$. Thus the total resistance reduction was $1.8 \mathrm{M} \Omega$. Reponse time to target gas (defined as time required for $90 \%$ reduction of total resistance reduction) is $48 \mathrm{~s}$ and recovery time (defined as time required to get back to original resistance in air i.e. $\left.R_{\text {air }}\right)$ is $3 \mathrm{~min}$. 


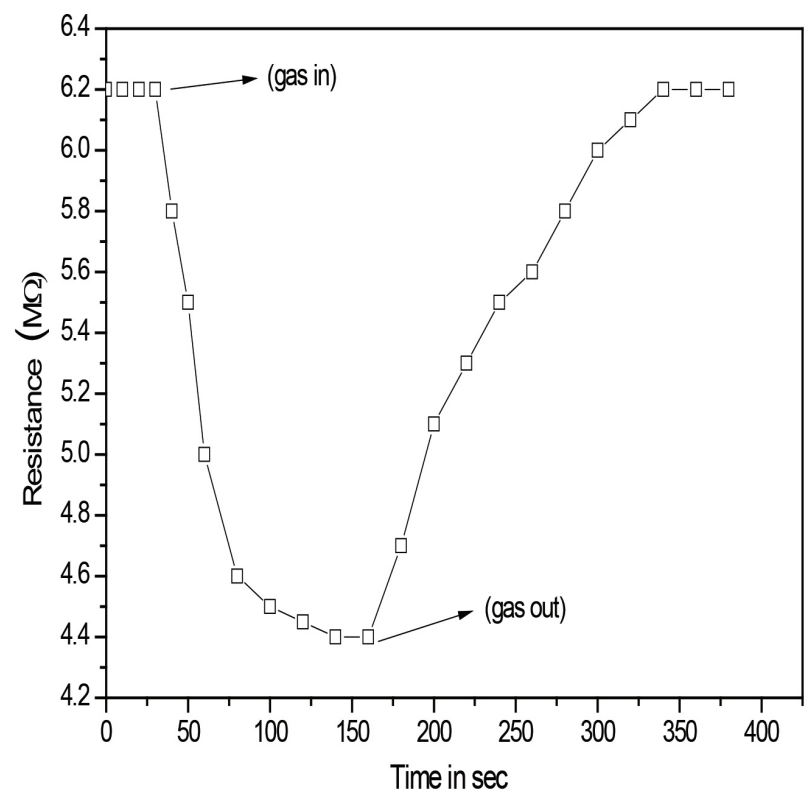

Figure 6: Response and recovery characteristics of $80^{\circ} \mathrm{C}$ bath temperature deposited $\mathrm{AgO}$ thin film at $250^{\circ} \mathrm{C}$ in presence of $400 \mathrm{ppm}$ alcohol.

\section{CONCLUSION}

Polycrystalline AgO thin film was synthesised by CBD technique. Deposition temperature was found to influence the microstructure strongly. Higher deposition temperature results in lowering of particle size and higher porosity. Such porous polycrystalline thin film with small particle size is particularly suitable for their application as gas sensing material. The sensitivity was found to be a function of operating temperature of the sensor material and maximum sensitivity was observed at $\sim 250^{\circ} \mathrm{C}$. A maximum sensitivity for $\sim 35 \%$ was observed in presence of $1000 \mathrm{ppm}$ ethanol at this temperature. The material shows reasonably fast response and recovery.

\section{ACKNOWLEDGEMENTS}

Authors Mahima Ranjan Das acknowledges the University Grants Commission (UGC), India for proving Junior Research Fellowship (Ref. No. 21/12/2014(ii)EUV) during the work. The authors wish to acknowledge the UGC, India, for granting 
Centre for Advanced Study (CAS) under the thrust area Condensed Matter Physics Including Laser Applications to the Department of Physics, University of Burdwan, India (No F. 530/5/CAS/2011(SAP-I)).

\section{REFERENCES}

1. Fekkai, Z., Mustapha, N. \& Hennache, A. (2014). Optical, morphological and electrical propertiesof silver and aluminum metallization contacts for solar cells. Am. J. Mod. Phys., 3(2), 45-50.

2. Hou, S. M., Ouyang, M. \& Chen, H. F. (1998). Fractal structure in the silver oxide thin film. Thin Solid Films, 315(1-2), 322-326.

3. Tominaga, J. (2003). The application of silver oxide thin films to Plasmon photonic devices. J. Phys. Condens. Mater., 15(7), 1101-1106.

4. Li, F. et al. (2009). Mechanism of droplet generation in silver thin films for organic light-emitting diode displays. Thin Solid Film, 517(9), 2941-2944.

5. Murray, B. J. et al. (2005). Silver oxide microwires: Electro deposition and observation of reversible resistance modulation upon exposure to ammonia vapor. Chem. Mater., 17(26), 6611-6618.

6. Dellasega, D. et al. (2008). Nanocrystaline silver oxide thin film of antibactrerial activity. Nanotechnol., 19(47), 475602-475608.

7. Parkhurst, W. A., Dallek, S. \& Larrick, B. F. (1984). Thermo-gravimetryevolved gas analysis of silver oxide cathode material. J. Electrochem. Soc., 13(8), 1739-1742.

8. Ida, Y. et al. (2008). Direct electro-deposition of $1.46 \mathrm{ev}$ band gap silver (i) oxide semiconductor films by electro generated acid. Chem. Mater., 20(10), 1254-1258.

9. Al-kuhaili, M. F. (2007). Characterization of thin films produced by the thermal evaporation of silver oxide. J. Phys. D Appl. Phys., 40(9), 28472853.

10. Raju, N. R., Kumar, K. J. \& Subrahmanyam, A. (2009). Physical properties of silver oxide thin films by pulsed laser deposition: Effect of oxygen pressure during growth. J. Phys. D Appl. Phys., 42(13), 135411-135417.

11. Gordon, R. (1997). Chemical vapor deposition of coatings on glass. J. NonCrystal. Solid, 218(1-3), 81-91.

12. Jelić, D. et al. (2010). A thermo gravimetric study of reduction of silver oxide under non-isothermal conditions. Contemp. Mater., 1(2), 144-150.

13. Barik, U. K. et al. (2003) Electrical and optical properties of reactive DC magnetron sputtered silver oxide thin films: Role of oxygen. Thin Solid Films, 429(1-2), 129-134. 
14. Saroja, G., Vasu, V. \& Nagarani, N. (2013). Optical studies of $\mathrm{Ag}_{2} \mathrm{O}$ thin film prepared by electron beam evaporation method. O. J. Metal, 3, 57-63.

15. Varkey, A. J. \& Fort, A. F. (1993). Some optical properties of silver peroxide $(\mathrm{AgO})$ and silver oxide $\left(\mathrm{Ag}_{2} \mathrm{O}\right)$ films produced by chemical-bath deposition. Solar Ener. Mater. Solar Cells, 29, 253-259.

16. Ezenwa, I. A., Obiagauzo, P. O. \& Ebeh, L. N. (2015). Synthesis and optical characteristics of $\mathrm{AgO}$ thin films fabricated by chemical bath deposition method. Int. J. Inno. Technol. Res., 3, 2220-2223.

17. Zhang, Y. et al. (2012). The ethanol sensing characteristics of $\mathrm{ZnO}$ thin films with low operating temperatures synthesized by pulsed laser deposition. Meas. Sci. Technol., 23, 105107-105114.

18. Sahay, P. P. et al. (2005). Sprayed $\mathrm{ZnO}$ thin films for ethanol sensors. $J$. Mater., 40, 4791-4793.

19. Hellegouarc'h, F. et al. (2001). PECVD prepared $\mathrm{SnO}_{2}$ thin flms for ethanol sensors. Sens. Actuat. B, 73, 27-34.

20. Pawar, N. K. et al. (2012). Nanostructured $\mathrm{Fe}_{2} \mathrm{O}_{3}$ Thick film as ethanol sensor. Int. J. Smart Sensing Intell. Syst., 5, 441-457.

21. Parmer, M. \& Rajanna, K. (2011). Copper (II) oxide thin film for methanol and ethanol sensing. Int. J. Smart Sens. Intel. Syst., 4, 710-725.

22. Nwanya, A. C. et al. (2013). Structural and optical properties of chemical bath deposited silver oxide thin films: Role of deposition time. Adv. Mater. Sci. Eng., Article ID 450820-828.

23. Mitra, P. \& Khan, J. (2006). Chemical deposition of $\mathrm{ZnO}$ films from ammonium zincate bath. Mater. Chem. Phys., 98, 279-284.

24. Chemistry and Technology. (2017). Retrieved from http://chemister.ru/ Database/properties-en on 20 January 2016.

25. Kamble, R. B. \& Mathe, V. L. (2008). Nanocrystalline nickel ferrite thick film as an efficient gas sensor at room temperature. Sens. Actuat. B, 131, 205-209.

26. Ifeanyichukwu, C. A. (2015). In-situ deposition, optical characterization and bandgap shift of AgO thin films. Chem. Mater. Res., 7, 1-8,

27. Cullity, B. D. (1972). Elements of X-ray diffraction. Massachusetts: AddisonWesley.

28. Klug, H. P. \& Alexander, L. E. (1974). X-ray diffraction procedures for polycrystalline and amorphous materials. New York:Wiley.

29. Dhanam, M., Rajeev, R. P. \& Manoj, P. K. (2008). Investigations on chemical bath deposited cadmium selenide thin films. Mater. Chem. Phys., 107, 289296.

30. Tauc, J. (1974). Amorphous and liquid semiconductor. New York: Plenum Press. 
31. Ghosh, B. et al. (2008) Fabrication and optical properties of SnS thin films by SILAR method. Appl. Surf. Sci., 254, 6436-6440.

32. Rezlescu, N. et al. (2009). Gas sensing properties of porous $\mathrm{Cu}-, \mathrm{Cd}-$ and Zn- ferrites. Roman. Rep. Phys., 61, 223-234.

33. Chou, S. M. et al. (2006). Thin film gas sensor for detection of ethanol. Vap. Sens., 6, 1420-1427.

34. Kale, S. S. et al. (2007). Preparation and characterization of ZnTe thin films by SILAR method. Appl. Surf. Sci., 253, 4335-4337.

35. Arshak, K. \& Gaidan, I. (2006). NiO/ $/ \mathrm{Fe}_{2} \mathrm{O}_{3}$ polymer thick films as room temperature gas sensors. Thin Solid Films, 495, 286-291.

36. Xiangfeng, C., Dongli, J. \& Chenmou, Z. (2007) The preparation and gassensing properties of $\mathrm{NiFe}_{2} \mathrm{O}_{4}$ nanocubes and nanorods. Sens. Actuat. B, 123, 793-797. 